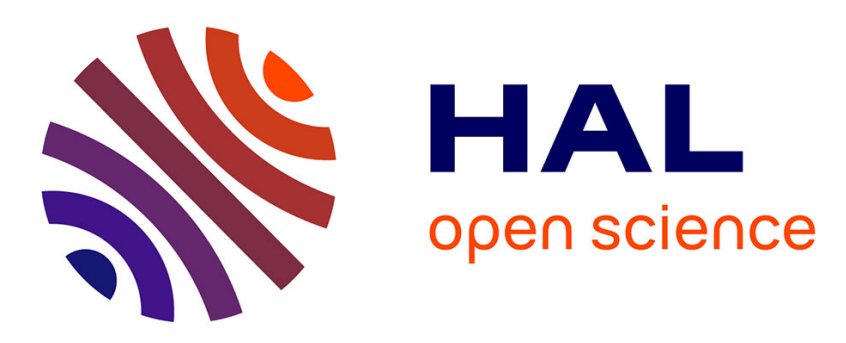

\title{
Microgrid modeling and power quality enhancements using low-level control methods based on robust RST controller
}

Rémy Vincent, Mourad Aït-Ahmed, Azeddine Houari, Mohamed Fouad Benkhoris

\section{To cite this version:}

Rémy Vincent, Mourad Aït-Ahmed, Azeddine Houari, Mohamed Fouad Benkhoris. Microgrid modeling and power quality enhancements using low-level control methods based on robust RST controller. IECON 2018 - 44th Annual Conference of the IEEE Industrial Electronics Society, Oct 2018, Washington, DC, United States. pp.213-218, 10.1109/IECON.2018.8591832 • hal-02135186

\section{HAL Id: hal-02135186 \\ https://hal.science/hal-02135186}

Submitted on 21 May 2019

HAL is a multi-disciplinary open access archive for the deposit and dissemination of scientific research documents, whether they are published or not. The documents may come from teaching and research institutions in France or abroad, or from public or private research centers.
L'archive ouverte pluridisciplinaire HAL, est destinée au dépôt et à la diffusion de documents scientifiques de niveau recherche, publiés ou non, émanant des établissements d'enseignement et de recherche français ou étrangers, des laboratoires publics ou privés. 


\section{Microgrid modeling and power quality enhancements using low-level control methods based on robust RST controller}

\author{
Remy Vincent \\ IREENA / ICAM Site de Nantes \\ Universite de Nantes \\ 35 Avenue du Champ de Manœuvre, Carquefou, France \\ remy.vincent@icam.fr
}

Mohamed Fouad Benkhoris

IREENA

Universite de Nantes

Saint-Nazaire, France

mohamed-fouad.benkhoris@univ-nantes.fr

\author{
Mourad Ait-Ahmed \\ IREENA \\ Universite de Nantes
}

Saint-Nazaire, France

\author{
Azeddine Houari \\ IREENA \\ Universite de Nantes \\ Saint-Nazaire, France
}

mourad.ait-ahmed@univ-nantes.fr azeddine.houari@univ-nantes.fr

\begin{abstract}
The electric grids are in constant mutation and are heading towards more smartness to ensure different objectives such as: better integration of renewable energy (RnE), balance management for supply and demand, reduction of greenhouse gases (GHG), power quality enhancement, security of energy supply for the consumer. This paper purposes is to illustrate the role of a robust low-level control in term of power quality enhancement of micro-grid based on photovoltaic source and battery storage system. The concept of smart microgrid (MG) is firstly discussed, and then the studied MG elements are modeled. A centralized control scheme is presented and the controller design is detailed. A robust RST controller is proposed where its effectiveness is compared to a classical PI controller through simulations tests.
\end{abstract}

Index Terms-Microgrids, Power generation, Renewable energy sources, Batteries, PI Controller, RST Controller.

\section{INTRODUCTION}

The current electrical grid is desi gned for centralized power plants providing energy to loads that have predictable behavior. It will not be the case anymore in the future. The important share of Renewable Energy (RnE) sources and their intrinsic intermittent behavior will force grid operators to redesign the grid. There are two solutions: massive reinforcement of the current grid or going towards smart grid solutions. The first one will be costly and is not very suitable for the deployment of RnE-based Distributed Generation (DG) units. Besides, RnE penetration will increase power quality needs and smart microgrids (MG) are a good answer for that because they can enable local control of: loads, frequency, voltage as well as a rapid response of their storage system if they have any. A smart MG is a self-sustaining cluster of Distributed Energy Ressources (DER) and loads that operates as a whole control entity in both grid-connected and off-grid modes. This concept appeared in the literature in 2001 [1].
To ensure efficient operation and to satisfy objectives like standards and norms such as IEEE 1547 (standard for interconnection between DG and utility grids) and EN 50160 (voltage characteristics guaranteed on European distribution networks), smart control methods have to be implemented. On way to deal with these constraints is to deploy a control hierarchy. hierarchy involves primary, secondary and tertiary control [2]. Primary control deals with system variables (voltage and frequency) and makes sure they track their set points and does not require communication abilities with other devices. Depending on the objective, various DG interface control methods can be implemented, such as: PQ, droop and V/f control [3]. These methods need controllers to ensure good dynamics. To design an appropriate controller, several possibilities are proposed in the literature. These include PI, $\mathrm{H} \infty$ [4], fuzzy logic and LQG [5] controllers.

This paper proposes a robust low-level control to enhance the power quality in a micro-grid based on photovoltaic source and a battery storage system. The battery system ensures the power balance between the RnE production and the supplied load. The robust controller considered in this paper is a polynomial RST controller where the feedback control actions $\mathrm{R}$ and $\mathrm{S}$ enhance the control robustness under uncertainties, while the polynomial $\mathrm{T}$ is introduced in the feedforward to improve the tracking performance.

The rest of the paper is organized as follow. Section II presents the studied MG and the components models in order to create a simulator where controllers are implanted. In Section III the proposed low-level controllers design methodology is detailed. Section IV presents comprehensive simulation results where the proposed controller performances are compared to a classical PI controller. Finally, section V underlines the contributions of this work. 


\section{COMPONENTS MODEL}

The studied hybrid MG involves a solar panel array, a storage system (lithium-ion battery rack), converters to supply DC bus, inverter to supply AC bus, 400 VAC 3-phase resistive load and switches to be make it able to operated in gridconnected mode with the Low Voltage (LV) utility grid. In this section, models used to realize the simulator are presented.

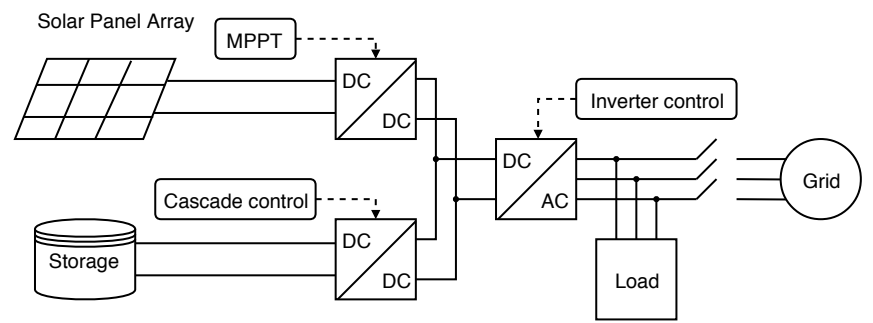

Fig. 1: Microgrid general scheme

\section{A. Solar panel array}

The single-diode with internal resistances model is one of the most commonly used in photovoltaic modeling. It delivers satisfying performance with a reasonable computation time [6], [7]. The solar cell is represented by the following diagram.

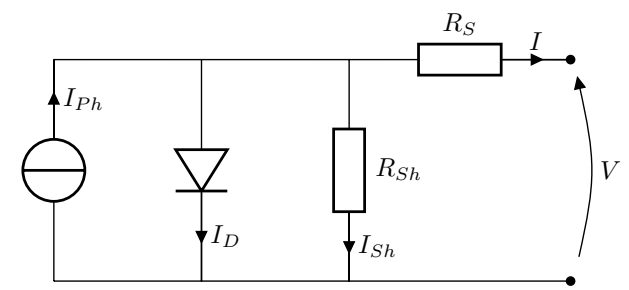

Fig. 2: Equivalent electrical circuit of the single-diode with internal resistances model.

The mathematical description of a photvoltaic panel circuit is given by the following equation:

$$
I=I_{P h}-I_{0} \cdot\left[\exp \left(\frac{V+R_{S} \cdot I}{A \cdot N_{s} \cdot V_{t}}\right)-1\right]-\frac{V+R_{S} \cdot I}{R_{S h}}
$$

where:

- $I$ is the load current (A).

- $V$ is the output voltage (V).

- $I_{P h}$ is the solar induced current (A).

- $I_{0}$ is the diode reverse saturation current (A) (supplier data or computed).

- $N_{s}$ the number of cells in series;

- $A$ is the diode's quality factor (1 if ideal diode).

- $V_{t}=\frac{K . T}{q}$ with:

- $K$ the Boltzmann constant.

- $T$ is the temperature of the $\mathrm{P}-\mathrm{N}$ junction $\left({ }^{\circ} \mathrm{K}\right)$.

- $q$ is the elementary charge (C).

- $R_{S}$ is the series resistance $(\mathrm{Ohm})$.
- $R_{S h}$ is the shunt resistance $(\mathrm{Ohm})$.

$I_{P h}$ can be described by the following formula:

$$
I_{P h}=\left(I_{s c-r e f}+C_{i} \cdot\left(T_{c}-T_{r e f}\right) \cdot \frac{G}{1000}\right.
$$

with:

$$
T_{c}=T_{a m b}+(N O C T-293) \cdot \frac{G}{800}
$$

where:

- $I_{s c-r e f}$ is the reference short circuit current (A).

- $C_{i}$ is the current coefficient $\left(\mathrm{A} \mathrm{K}^{-1}\right)$.

- $T_{c}$ is the cell temperature $\left({ }^{\circ} \mathrm{K}\right), T_{a m b}$ is the ambient temperature and $T_{r e f}\left(298{ }^{\circ} \mathrm{K}\right)$ is the reference ambient temperature used for solar panel ratings.

- $G$ is the solar irradiation received by the panel $\left(\mathrm{W} \mathrm{m}^{-2}\right)$.

- NOCT means "Nominal Operating Cell Temperature" $\left({ }^{\circ} \mathrm{K}\right)$.

The saturation current $I_{0}$ can be computed as follows:

$$
I_{0}=I_{r s} \cdot{\frac{T_{c}}{T_{r e f}}}^{\frac{3}{A}} \cdot \exp \left(\frac{E_{g} \cdot q \cdot\left(\frac{1}{T_{r e f}}-\frac{1}{T_{c}}\right)}{A \cdot K}\right)
$$

with:

$$
I_{r s}=\frac{I_{s c-r e f}+C_{i} \cdot\left(T_{c}-T_{r e f}\right)}{\exp \left(\frac{V_{o c-r e f}+C_{v} \cdot\left(T_{c}-T_{r e f}\right)}{A \cdot V_{t} \cdot N_{s}}\right)-1}
$$

where:

- $E_{g}$ is the electron band gap $(\mathrm{eV})$.

- $C_{v}$ is the voltage coefficient $\left(\mathrm{V} \mathrm{K}^{-1}\right)$

\section{B. Batteries}

Battery model which was used is a classic battery model described in [8]. It uses two equations (for charge and discharge) to represent the behavior of a standard lithium-ion battery.

$f_{1}(i t, i *, i)=E_{0}-K \cdot \frac{Q}{Q-i t} \cdot i *-K \cdot \frac{Q}{Q-i t} \cdot i t-R \cdot i+A \cdot \exp (-B . i t)$

$f_{2}(i t, i *, i)=E_{0}-K \cdot \frac{Q}{i t-\frac{Q}{10}} \cdot i *-K \cdot \frac{Q}{Q-i t} \cdot i t+A \cdot \exp (-B \cdot i t)$

Where $f_{1}$ is used when $i *>0$ (discharge), $f_{2}$ is used when $i *<0$ (charge) and:

- $E_{0}$ is constant voltage $(\mathrm{V})$.

- $K$ is polarization constant or polarization resistance $\left(\mathrm{V} \mathrm{A}^{-1} \mathrm{~h}^{-1}\right.$ or $\Omega$ ).

- $i *$ is low frequency current dynamics (A).

- $i$ is battery current (A).

- it is present battery charge (A h).

- $Q$ is maximum battery capacity (A h).

- $A$ is exponential voltage $(\mathrm{V})$.

- $B$ is exponential capacity $\left(\mathrm{A}^{-1} \mathrm{~h}^{-1}\right)$. 


\section{Buck/Boost converter}

The Buck/Boost converter is used to control the DC link voltage in order the respect its value set by the MG user. In this article, two converters are used to boost both PV panel array and batteries respective voltage. The converter connected to the PV panel array is used only in boost mode, thus the upper MOSFET in Figure 3 can be replaced by a simple diode in this case. Buck/boost converter dynamics are characterized by

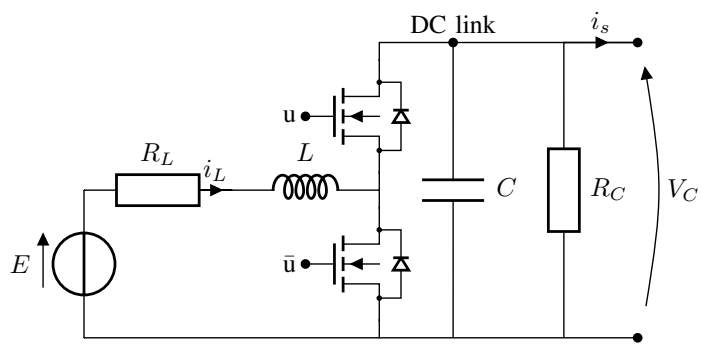

Fig. 3: Electrical circuit of a buck/boost converter with a voltage source and a DC link part.

the following formulas:

$$
\begin{gathered}
L \frac{\mathrm{d} i_{L}}{\mathrm{~d} t}=E-\alpha \cdot V_{C}-R_{L} \cdot i_{L} \\
C \frac{\mathrm{d} V_{C}}{\mathrm{~d} t}=\alpha \cdot i_{L}-\frac{V_{C}}{R_{C}}-i_{s}
\end{gathered}
$$

with:

$$
\text { - }\langle u\rangle_{0}=\alpha \text { and }\langle\bar{u}\rangle_{0}=1-\alpha
$$

Linearizing equations (8) and (9) around an operation point (E is set as a constant) allows to represent both inner and outer plants with the following transfer functions [9]:

$$
\begin{gathered}
H_{\text {in }}=\frac{\tilde{I_{L}}(s)}{\tilde{\alpha}(s)}=\frac{K_{C}}{T_{C} \cdot s+1}=\frac{\frac{-V_{C}^{*}}{R_{L}}}{\frac{L}{R_{L}} \cdot s+1} \\
H_{\text {out }}=\frac{\tilde{V}_{C}(s)}{\tilde{I}_{L}(s)}=\frac{K_{V}}{T_{V} \cdot s+1}=\frac{\frac{E}{i_{s}}}{\frac{C \cdot V_{C}^{*}}{i_{s}} \cdot s+1}=\frac{\frac{R \cdot E}{V_{C}^{*}}}{R \cdot C \cdot s+1}
\end{gathered}
$$

with:

- $R$ is the supplied load's impedance (Ohms).

- $V_{C}^{*}$ is the reference DC link voltage $(\mathrm{V})$.

\section{Inverter}

The inverter performs DC to AC conversion to supply AC loads and/or the utility grid. Set point tracking is ensured by a controller depending on the simulation. LCL filter was chosen because of its ability to keep satisfying Total Harmonic Distortion (THD) ratio and it's design was made according to [10]. The inverter behavior expressed in dq space is represented by the following equations and it's physical topology is displayed in Figure 4:

$$
\begin{gathered}
V_{D C}\left[\begin{array}{l}
u_{d} \\
u_{q}
\end{array}\right]=L_{\text {inv }}\left[\begin{array}{c}
I_{\text {inv }} \cdot \\
I_{\text {inv }}
\end{array}\right]+\omega L_{\text {inv }}\left[\begin{array}{c}
-I_{\text {inv }} \\
I_{\text {inv }}
\end{array}\right]+\left[\begin{array}{l}
V_{C f_{d}} \\
V_{C f_{q}}
\end{array}\right] \\
C_{f}\left[\begin{array}{c}
V_{C f_{d}}^{\cdot} \\
V_{C f_{q}}
\end{array}\right]+\omega C_{f}\left[\begin{array}{c}
-V_{C f_{q}} \\
V_{C f_{d}}
\end{array}\right]=\left[\begin{array}{c}
I_{\text {inv }_{d}} \\
I_{\text {inv }}
\end{array}\right]-\left[\begin{array}{c}
I_{\text {out }_{d}} \\
I_{\text {out }_{q}}
\end{array}\right] \\
{\left[\begin{array}{c}
V_{C f_{d}} \\
V_{C f_{q}}
\end{array}\right]=L_{\text {out }}\left[\begin{array}{c}
I_{\text {out }} \\
I_{\text {out }_{q}}
\end{array}\right]+\omega L_{\text {out }}\left[\begin{array}{c}
-I_{\text {out }} \\
I_{\text {out }_{d}}
\end{array}\right]+\left[\begin{array}{l}
E_{\text {grid }_{d}} \\
E_{\text {grid }_{q}}
\end{array}\right]}
\end{gathered}
$$

\section{CONTROL}

\section{A. MPPT $P \& O$ algorithm for the boost converter}

The MPPT P\&O algorithm is commonly used to drive photovoltaic panel at their best point of operation thus increasing their efficiency [11]. In Figure 5, this algorithm is displayed with $D$ (boost converter duty ratio) as output.

\section{B. Cascade control for the buck/boost converter}

1) RST controller: RST is a robust controller set to control both inner and outer plants of the buck/boost converter. The controller scheme is displayed in Figure 6. R, S and T are computed from equations (15) and (16).

$$
\begin{gathered}
A(s) \cdot S(s)+B(s) \cdot R(s)=D(s)=C(s) \circledast F(s) \\
T(s)=\frac{R(1)}{F(1)} \cdot F(s)
\end{gathered}
$$

In equation (15), B and A are respectively numerator and denominator of the transfer function of the regulated system. $\mathrm{C}$ and $\mathrm{F}$ are respectively control and filtering polynomials obtained by pole placement. Pole placement is realized using time constants $T_{c}$ and $T_{f}$ for dynamics and filtering control [12]. An example of pole placement in order to obtain polynomial $C(s)$ is presented in Figure 7.

In this example (Figure 7), $s_{1}$ and $s_{2}$ are poles from $A(s)$. Pole $s_{1}$ stands has acceptable dynamics according to criteria $T_{c}$ and damping coefficient $\phi$ while pole $s_{2}$ has not, so presented transformations must be followed to find acceptable pole in order to generate polynomial $C(s)$. Here the final result is $C(s)=\left(s-s_{1}\right)\left(s-s_{2}^{\prime}\right)[12]$.

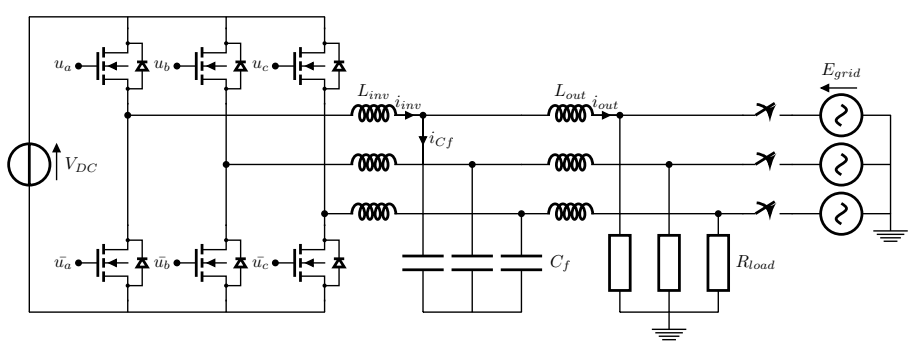

Fig. 4: Three phase grid tied inverter with an LCL filter supplying a resistive load and able to perform both islanded and grid connected operations. 


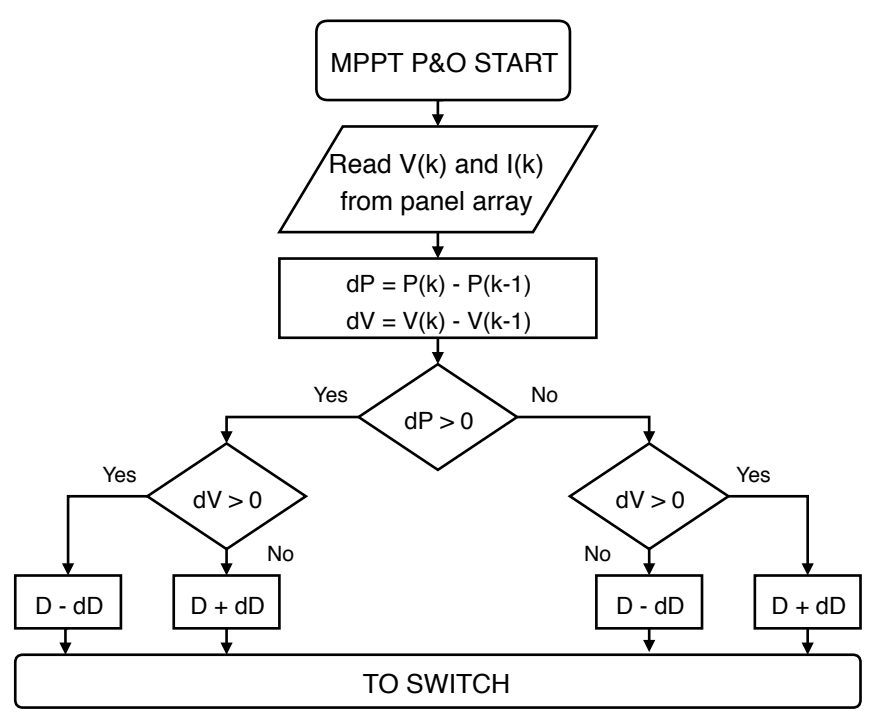

Fig. 5: MPPT P\&O algorithm

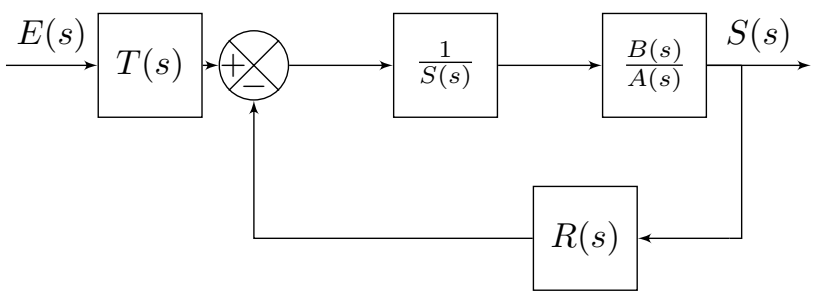

Fig. 6: RST control scheme

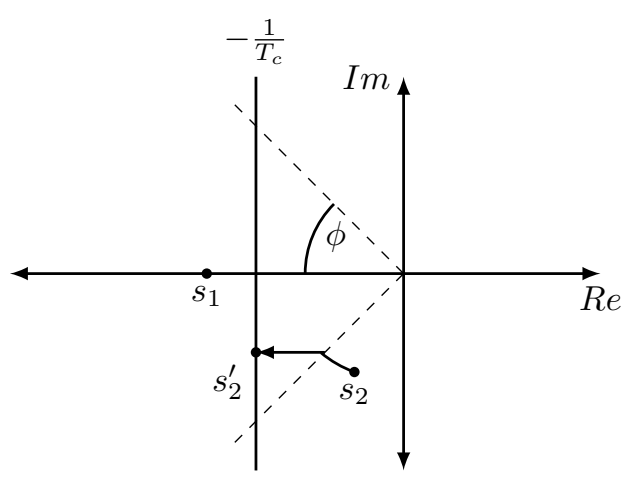

Fig. 7: RST controller robust pole placement example

2) PI controller: Current (inner) and voltage (outer) plants from the buck/boost are controlled with a cascade PI controller. Because of their first order (see equations (10) and (11)), PI controllers may be used to ensure both zero error in steady state and managed bandwidth. For both controllers, outer loop dynamics must be set slow enough to respect the inner loop dynamics (inner loop dynamics must be at least 5 times faster and preferably 10 times). Both current and voltage PI controllers are set thanks to pole placement method presented in [9]:

$$
\mathrm{PI}=K_{p} \cdot\left(1+\frac{1}{T_{i} . s}\right)
$$

with:

- $K_{p}$ is controller proportional coefficient.

- $T_{i}$ is controller integral time constant (s).

\section{C. $V / f$ and $P Q$ control methods for the inverter}

When the MG is islanded, the control system switches to $\mathrm{V} / \mathrm{f}$ control method to ensure both voltage and frequency on the AC side. PQ control method is used when the MG is in grid-connected mode because both voltage and frequency are set by the utility grid.

1) V/f control: To perform efficient V/f control means to determine correct set points for both AC voltage (in this work: $V_{\text {out }_{d q}}$ ) and signal phase (in this work: $\theta$ ) to ensure grid operation within norm thresholds. The process is quite simple. First of all, active $(\mathrm{P})$ and reactive $(\mathrm{Q})$ power consumed on the $\mathrm{AC}$ side are measured. Because these measures are instant values, it is recommended to apply a low-pass filter like $\frac{\omega_{c}}{s+\omega_{c}}$ (where $\omega_{c}$ is the low-pass filter's cut-off frequency) to get their fundamental components [13].

Then, both voltage $\left(V_{\text {out }_{d}}\right)$ and frequency $(\theta)$ set points can be computed using equations 18 and 19 .

$$
\begin{gathered}
\dot{\theta}=\omega=\omega_{n}+\frac{\omega_{\max }-\omega_{\min }}{P_{\max }} \cdot P \\
V_{\text {out }_{d}}=V_{n}+\frac{V_{\text {out }_{\text {max }}}-V_{\text {out }_{d \min }}}{Q_{\max }} \cdot Q
\end{gathered}
$$

Where:

- $\omega_{n}$ is the reference frequency $(\mathrm{Hz})$.

- $V_{n}$ is the nominal voltage point in d-axis $(\mathrm{V})$.

The control strategy is set as the output of voltage magnitude is set in the d-axis reference frame and q-axis is set to 0 , thus $V_{\text {out }_{q}}=0$. Finally, using equations (12), (13) and (14), general control is achieved thanks to both voltage and current loops.

2) $P Q$ control: As written above, $P Q$ control method is used when the MG is in grid-connected mode. This control is simpler than $\mathrm{V} / \mathrm{f}$ control because of voltage and frequency values are set by the utility grid. Thus this control focuses only on current values to supply AC load and utility grid. In Figure 8, PQ control using a current loop is displayed. Reference value for the given current loop is computed from equations (13) (neglecting capacitor dynamics) and (20). The current loop is realized using equation (12). In the example (i.e Figure 8), a RST controller is applied to deal with inductance dynamics.

$$
\begin{aligned}
& P=\frac{3}{2}\left(V_{\text {out }_{d}} \cdot I_{\text {out }_{d}}-V_{\text {out }_{q}} \cdot I_{\text {out }_{q}}\right) \\
& Q=\frac{3}{2}\left(V_{\text {out }_{q}} \cdot I_{\text {out }_{d}}-V_{\text {out }_{d}} \cdot I_{\text {out }_{q}}\right)
\end{aligned}
$$




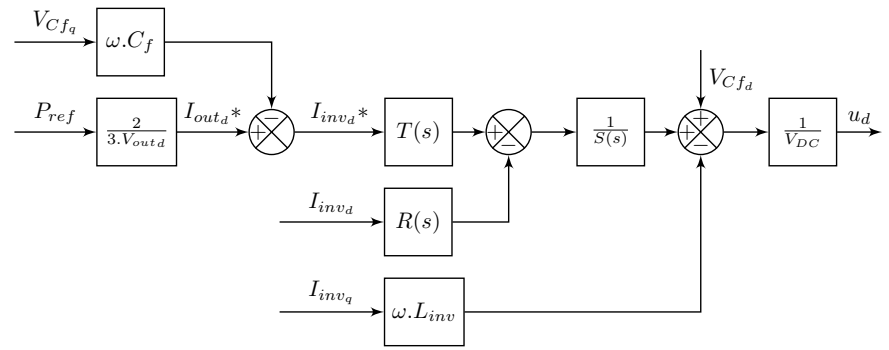

Fig. 8: PQ control method with RST controller applied to a current loop using equation (12) (only $\mathrm{P}$ is displayed here)

\section{RESULTS}

RST and PI controllers are compared in a MG operation scenario representing grid-connected operations. Presented results involve temporal response, THD and phase margin for both controllers. For PI controller, the damping coefficient of controlled closed-loop was set to 0.7 . In the case of robust RST controller, its filtering constant $T_{f}$ was set according to $T_{c}$, such as $T_{f}=T_{c} / 5$ and $T f=T_{c} / 10$.

\section{A. Scenario}

At the beginning, the MG was in islanded and in steady state mode, it was supplying its AC load thanks to power provided by photovoltaic panel array and extra solar power was handled by the storage (in Figure 9(b) battery is charged until $\mathrm{t}=0.2 \mathrm{~s}$ ). In the context of Demand Response (DR), a power request was submitted to the MG. It synced with the utilty grid (gridconnected mode). Then, control system performed a $10 \mathrm{~kW}$ active power injection as requested per the utility grid and its dynamic behavior is using PI or RST controllers is represented in Figure 9(c) (and in Figure 9(d) for the reactive part that was set to 0). Power provided by the solar panel array was not enough to supply both AC load and grid request, so extra power was taken from the battery (Figure $9(\mathrm{~b})$ : after $\mathrm{t}=0.2$ the battery SOC decreased due to significant power demand).

\section{B. Results analysis}

Results presented above shows that RST controller is superior to PI controller in terms of dynamics and overshoot. RST is able to handle overshoot in the $5 \%$ zone around the objective value while PI is unable to reach such values and generates an overshoot above 10\%. In Figures 9(a), 9(c), 9(d), 9(e) and 9(f), the RST-based cascade control ensured better control and less voltage deviation than the PI-based control. RST control provided better control for the whole MG in this scenario. Phase margin and THD results are displayed in Table I.

\begin{tabular}{|c|c|c|c|}
\hline Controller & Coefficient & Phase margin $\left(^{\circ}\right)$ & THD $(\%)$ \\
\hline PI & $\zeta=0.7$ & 67.2 & 12.88 \\
\hline \multirow{2}{*}{ RST } & $T_{f}=T_{c} / 5$ & 64 & 6.03 \\
& $T_{f}=T_{c} / 10$ & 68.4 & 4.47 \\
\hline
\end{tabular}

TABLE I: Phase margin and THD comparison
Both controllers provide enough phase margin to consider the controlled system robust enough to handle perturbations. THD threshold which includes harmonics up to rank 40 should never exceed $8 \%$ for LV networks [14]. According to presented results, RST controllers provide better overshoot handling and better THD during events such as power injection.

\section{CONClusion}

Simulation results showed that utilization of robust RST control methods provided better power quality during power requests whether it is applied on DC or AC devices (buck/boost converters or inverters). Thus, RST controller is a solution to enhance power quality in MGs when improvements are needed in the scope of low-level control. Future work will involve the present studied grid in a simpler form in order to apply higher control levels such as tertiary control. Tertiary control involves market signals, stochastic data from forecast models. The goal will be to provide control optimization in order to provide efficient management taking into account multiple criteria (economic sustainability, power quality criteria).

\section{REFERENCES}

[1] R. H. Lasseter, "Microgrids," in Power Engineering Society Winter Meeting, 2002. IEEE, vol. 1. IEEE, 2002, pp. 305-308.

[2] M. Mahmoud, Microgrid: Advanced Control Methods and Renewable Energy System Integration. Elsevier Science \& Technology Books, 2016.

[3] W. Huang, M. Lu, and L. Zhang, "Survey on microgrid control strategies," Energy Procedia, vol. 12, pp. 206 - 212, 2011, the Proceedings of International Conference on Smart Grid and Clean Energy Technologies (ICSGCE 2011. [Online]. Available: http://www.sciencedirect.com/science/article/pii/S1876610211018558

[4] Q. L. LAM, A. I. Bratcu, and D. Riu, "Frequency robust control in stand-alone microgrids with PV sources : design and sensitivity analysis," in Symposium de Genie Electrique, Grenoble, France, Jun. 2016. [Online]. Available: https://hal.archives-ouvertes.fr/hal-01361556

[5] "Real-time validation of a robust lqg based decentralized supplementary control loop to mitigate instability in an islanded ac microgrid," Energy Procedia, vol. 117, pp. 535 - 542, 2017.

[6] M. S. Benghanem and S. N. Alamri, "Modeling of photovoltaic module and experimental determination of serial resistance," 2008.

[7] H. Patel and V. Agarwal, "Matlab-based modeling to study the effects of partial shading on pv array characteristics," IEEE transactions on energy conversion, vol. 23, no. 1, pp. 302-310, 2008.

[8] O. Tremblay and L.-A. Dessaint, "Experimental validation of a battery dynamic model for ev applications," World Electric Vehicle Journal, vol. 3 , no. 1 , pp. $1-10,2009$

[9] S. Bacha, I. Munteanu, and A. I. Bratcu, Power Electronic Converter Modeling and Control - with Case Studies, ser. Advanced Textbooks in Control and Signal Processing. Springer, Sep. 2013. [Online]. Available: https://hal.archives-ouvertes.fr/hal-00848243

[10] M. Liserre, F. Blaabjerg, and S. Hansen, "Design and control of an lc1filter-based three-phase active rectifier," IEEE Transactions on industry applications, vol. 41, no. 5, pp. 1281-1291, 2005.

[11] A. K. Abdelsalam, A. M. Massoud, S. Ahmed, and P. N. Enjeti, "High-performance adaptive perturb and observe mppt technique for photovoltaic-based microgrids," IEEE Transactions on Power Electronics, vol. 26, no. 4, pp. 1010-1021, 2011.

[12] P. de Larminat, Analysis and Control of Linear Systems, ser. ISTE. Wiley, 2010. [Online]. Available: https://books.google.fr/books?id=lzjt4niL5IC

[13] N. Pogaku, M. Prodanovic, and T. C. Green, "Modeling, analysis and testing of autonomous operation of an inverter-based microgrid," IEEE Transactions on Power Electronics, vol. 22, no. 2, pp. 613-625, March 2007.

[14] AFNOR, "European standard EN 50160," Tech. Rep., 2011. 


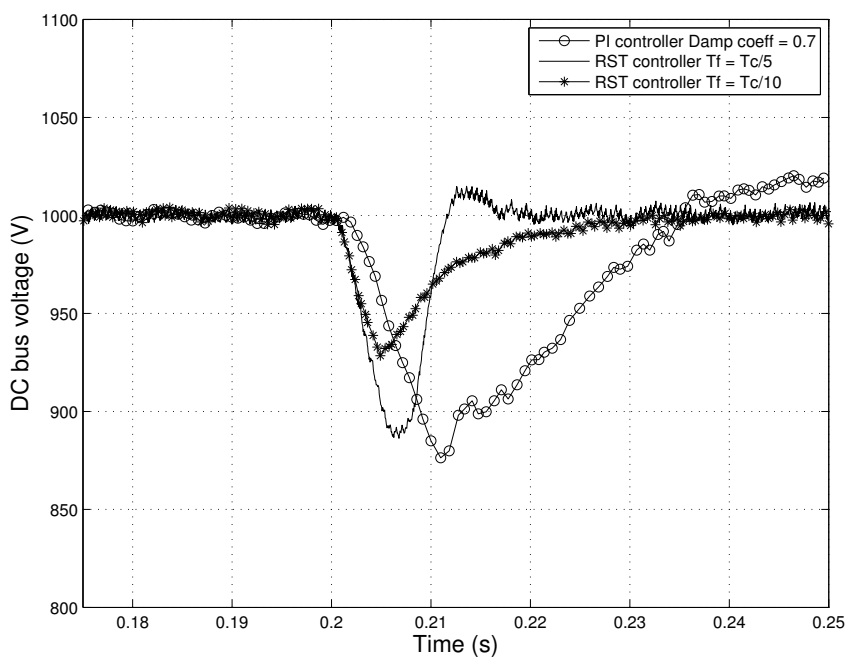

(a) Controller comparison regarding DC bus voltage

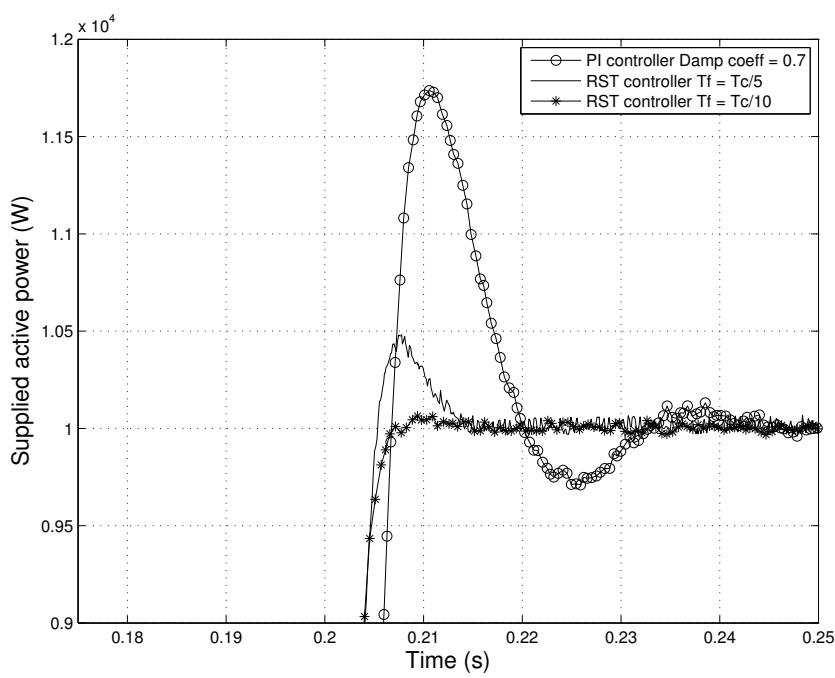

(c) Controller comparison regarding active power injection

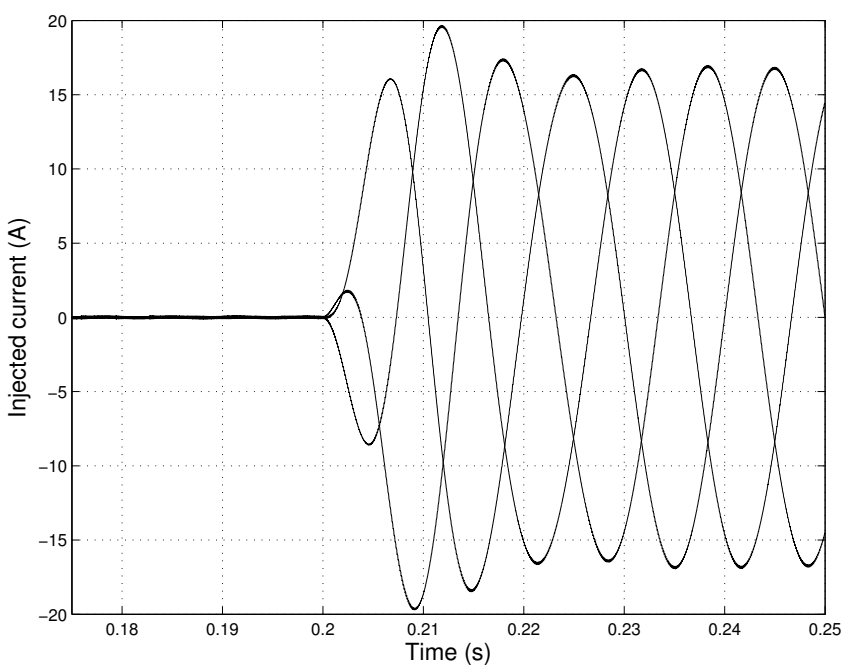

(e) Current waveform during injection on the grid side (PI)

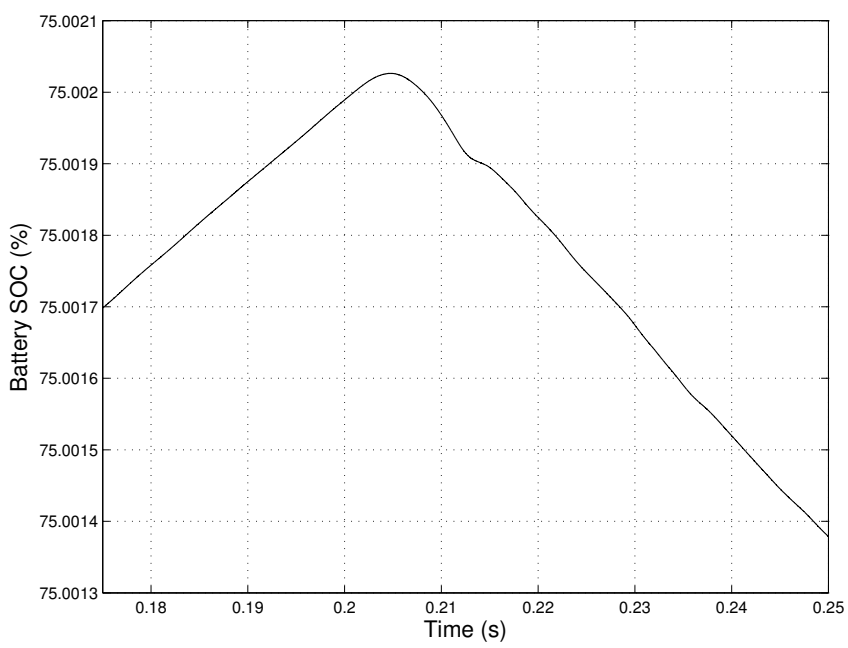

(b) Battery State Of Charge (SOC) evolution

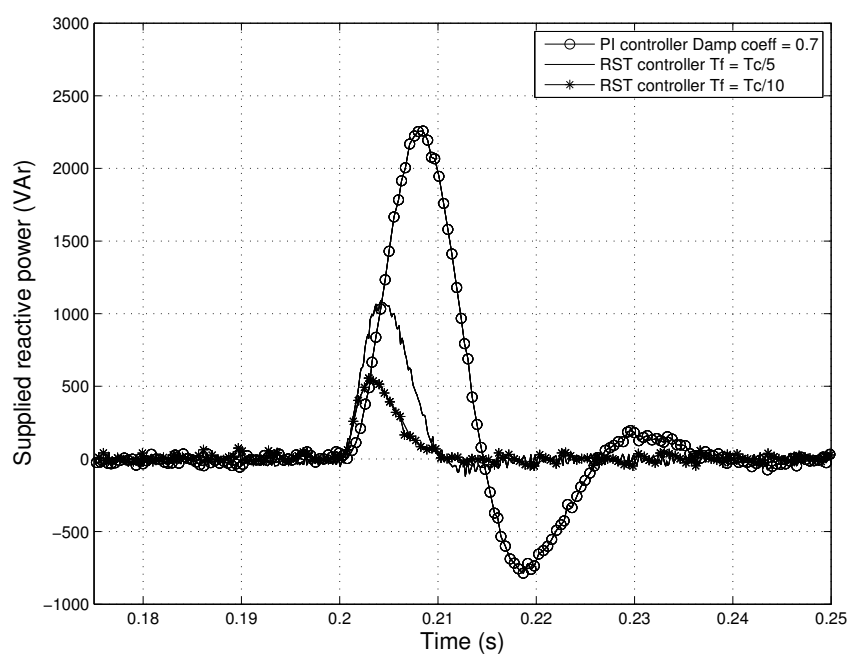

(d) Controller comparison regarding reactive power injection

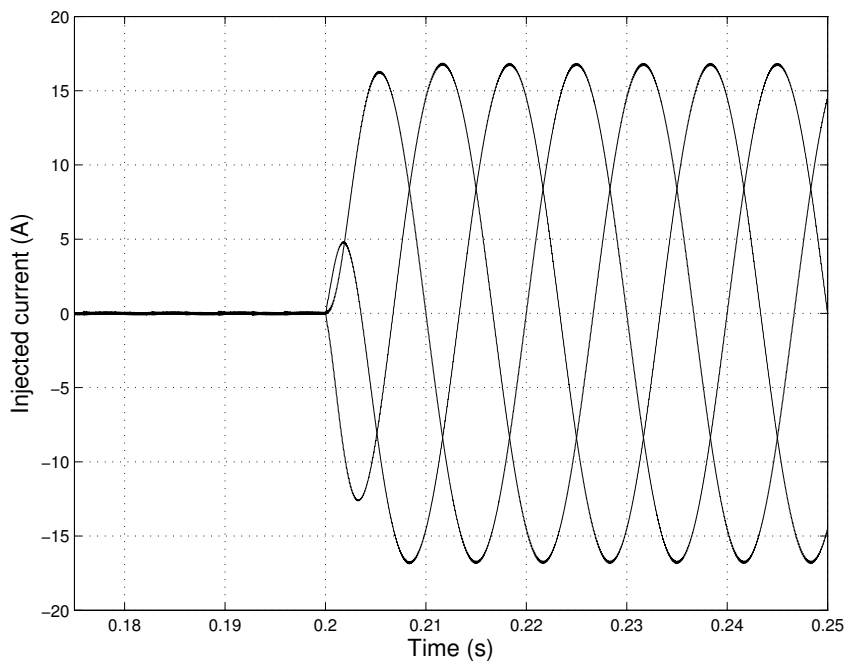

(f) Current waveform during injection on the grid side ( $\left.\mathrm{RST}_{T_{c} / 10}\right)$

Fig. 9: Robust RST and PI controllers comparisons 